\title{
Media events, speech events and propagandistic techniques of legitimation: a multimodal analysis of the Greek Prime Minister Kyriakos Mitsotakis' public addresses on the SARS-CoV-2 pandemic
}

\author{
Stamatis Poulakidakos ${ }^{1 \times}$
}

The increased information need after the outburst of the SARS-CoV-2 pandemic has led to the enhanced role of public addresses and press conferences that can broadcast important information simultaneously to a large number of people through a number of different media outlets (TV, radio, internet). Thus, government leaders worldwide have opted for the frequent broadcast of public addresses, reviving the rationale of media events as a way to disseminate their messages concerning the pandemic as widely as possible. The current paper focuses on the Greek case, scrutinizing the public addresses of the Greek PM Kyriakos Mitsotakis in terms of both structural and content characteristics. Through the use of multimodal analysis, we figure out the visual and linguistic characteristics in K. Mitsotakis public addresses. At the same time, we setup a research framework for the qualitative and quantitative examination of similar public addresses in various countries, by combining the theories of media events, propaganda, and linguistic techniques of political legitimization. Our main findings suggest that $\mathrm{K}$. Mitsotakis in his public addresses has made use of direct visual and verbal connections to aspects of "Greekness" in a nation-centric rationale. He relies predominantly on the evocation of positive sentiments and rationalization (as a means of legitimization), in order to achieve political benefits by incorporating the management of the pandemic into the Greek government's nationalist agenda.

\footnotetext{
${ }^{1}$ University of Western Macedonia, Kastoria, Greece. ${ }^{凶}$ email: s.poulakidakos@gmail.com
} 


\section{Introduction}

he SARS-CoV-2 pandemic broke out as a "holistic event" affecting all socio-economic, political, and cultural institutions and almost every aspect of daily life on a local, national as well as international level (Demertzis, 2020). Mainly due to its holistic character, the pandemic is an event whichamong other things - is strongly mediated, as its criticality has placed it at the top of the media agenda. The extremely critical character of the pandemic, due to the uncertainties that ontologically govern it, reinforce exponentially the public's need for orientation, which has been influenced-according to the agendasetting theory-by two major factors: the relevance of the news to citizens concerns, and the uncertainty that the individual feels towards the subject of the news (Severin and Tankard, 2014). As in the case of the pandemic, high relevance, and high uncertainty lead to a strong need for guidance, resulting in the subsumption of the individuals in the priorities of the media (Demertzis, 2002, p. 111; Valenzuela and McCombs, 2019).

In the case of Greece, this strong need for orientation is served by a media system that has as its dominant feature the "intense political parallelism" (Hallin and Mancini, 2004), resulting in the coverage of events through the intense reproduction of official (political) sources (e.g., Minister of Health, Prime Minister). In addition, Kyriakos Mitsotakis, leader of the right-wing party of New Democracy and PM of Greece since July 2019, has adopted a rather "aggressive" control policy of mainstream media in Greece, evidenced by placing the public Athenian/Macedonian News Agency (AMNA) and the Greek PBS (ERT) under his direct control immediately after his electoral victory (ThePressproject.gr, 2019). At the same time, he has been disseminating significant amounts of money-for a total of approximately 30 million euros-to print, audiovisual and internet media with opaque criteria, overtly favoring supportive media, which received about $99 \%$ of the funding (ThePressproject.gr, 2020), in order to disseminate "social" messages about the pandemic that under the Greek television regulatory framework should be disseminated by the media for free.

In terms of dealing with the pandemic, the conservative government of New Democracy was quick to impose a general lockdown from 23 March to early May 2020, which managed to intercept rather successfully the first wave of the pandemic, given that Greece was much less exposed to global transactions during the winter of 2019-2020 (Demertzis and Eyerman, 2020). Though the Greek government has been investing heavily-in communication terms-on this early success ever since, the second semester of 2020 was not that successful. Following the need to keep tourism open during the summer of 2020 without the implementation of massive COVID tests in the "gates" of the country (airports, border stations), the COVID cases were on a steady increase from August 2020 to mid-November, when the daily recorded cases reached the record number of 3316, on November 12, 2020 (covid19.gov.gr, 2020).

On November 7, 2020, a second lockdown was imposed, which is actually active up to the time this paper was written (early April 2021), only with minor loosening of the restrictive measures, mainly during the 2020 Christmas period. Though the current crisis is first and foremost a health crisis, and consequently a financial and social crisis, the Mitsotakis administration has been trying to deal with it primarily through the implementation of restrictive measures (lockdowns, curfews, prohibition of public gatherings/demonstrations), and secondarily through the implementation of rather limited enhancements in vital infrastructures, like the national health system, the public transportation means, and public education.

Within the abovementioned context in Greece, the audience's need to be guided around the pandemic has been largely met by the so-called "traditional" media and especially through television" This condition makes K. Mitsotakis televised public addresses an interesting case study, since he chose to address the public regarding the pandemic quite often, no less than 10 times in 8 months, an average of more than one public address per month. Thus, we will focus on the Greek Prime Minister Kyriakos Mitsotakis televised public addresses on the pandemic, both in terms of their structure and content, in an attempt to outline the formulation of the Greek PMs narrative about the coronavirus.

The main reason behind our focus on K. Mitsotakis public addresses is that these public discourse instances have (re)gained their importance at an international level, due to the condition of the pandemic, bringing forth the role of media events in the political communication procedure (Garland and Lilleker, 2021; Kalsnes and Skogerbø, 2021; Ólafsson, 2021; Eibl and Gregor, 2021). As these public addresses are "key" instances in the context of informing the public about the government strategy to deal with the pandemic and constitute major sources of information about the developments around the pandemic, we approach them as propagandistic media and speech events (Dayan and Katz, 1992; van Leeuwen, 2007; Mey, 2001). This approach enables us to shed light on the ways in which these public addresses act as carriers of (nationalist) governmental propaganda in terms of fighting the COVID pandemic, through their attempt to legitimize the Greek government's strategy to tackle the pandemic.

\section{Media events, speech events, propaganda}

With a view to understand, primarily the function of media events, it is useful to remember that reality is impossible to be approached in its entirety by individuals: "The world we are dealing with is out of reach, out of sight, out of mind. It must be explored, recorded, created through imagination" (Lippmann, 1988 , p. 34). Therefore, a fundamental form of power in modern societies is the power to define and represent this reality, and this very "power" lies in the hands of the Media (Poster, 1990; Debord, 1994; Berkowitz, 1997; Couldry, 2000; Luhmann, 2000). The practical manifestation of this "power" of the Media is described by the term "mediation", which signifies the cumulative impact of the Media on social life (Thompson, 1999; Silverstone, 2002); both at the level of producing and disseminating information on aspects of society which cannot be "reached" by the individualized "intellect", as well as at the level of the effects that the Media exert on the structure and the way social institutions function (Couldry, 2008, p. 377). According to this approach, the term mediation is understood as the way in which the Mediaboth in print and in electronic form-have "invaded" our lives, supplying us with information and symbols (Debord, 1994; Couldry, 2008), especially for processes and events that take place within society and we as individuals cannot witness. Consequently, "media events" are a manifestation of the mediation process, in the sense that the Media are the privileged carriers of messages regarding these events.

Lang and Lang were the first who observed empirically and analyzed the difference between directed television coverage and the live experience of an event (Katz and Dayan, 2006, p. 195). They studied General MacArthur's Chicago reception television coverage concluding that the television audience's enthusiasm did not correspond to the non-mediated reality. The first coherent and critical overview of media events can be found in the analysis of Boorstin (1989), who, having in mind the inherently commercial nature of the Media and, thus, of information, spoke of the need for fabrication of news by the Media. The satisfaction of this need has brought about the term "pseudo-events", namely 
events that occupy the public sphere and are generated by both communication professionals and politicians (Boorstin, 1989; Bennett, 1999). According to Boorstin, the pseudo-event is preplanned, directed, aiming at its transmission and it is usually repeatable and adapted to the "needs" of the "average" viewer or reader.

A much less critical evolution of Boorstin's approach is Dayan and Katz's theory of media events (1992), according to which "media events" are events that originally take place "outside" the Media, that is, real events that are not organized by the Media, and within society; they are broadcast live and take place away from their audiences. Media events have their own grammar, their own structure of meaning (story or script format), and a set of characteristics that take shape through live broadcast: they constitute an interruption of the daily programs and routines of the Media, they are based on "script" and organized in advance, they address and gather large audiences (Sumiala and Korpiola, 2016 , p. 33), they contain social and regulatory expectations related to the projected event, they are characterized by a ritual tone of narration and they intend to "unite" their audiences into a large whole (Dayan and Katz, 1992, pp. 5-9) on a primarily nationalist rationale (Poulakidakos, 2014, pp. 79-82). Nationalism, the ideological basis of the creation and consolidation of nation-states, is understood as a political ideology of modernity marked by three basic assumptions: (a) humanity is divided into individual nations, each of which has specific characteristics, (b) the nation must be organized in a sovereign state, (c) the interests of the nation occupy a paramount position and demand the highest loyalty to any other value (Demertzis, 1997, p. 15). Therefore, an important parameter of the "media events" is that their "grammar" is integrated into native (nation-centric) semantic structures of any given social culture (Dayan and Katz, 1992, pp. 28-29). Given the inherent focus of the media events theory on television, messages conveyed through media events constitute a combination of discursive and visual (political) communication. Politics has always had a visual dimension, and in an age of information overload where around $79 \%$ of earth's population has access to television and $51 \%$ has Internet access, the image may be an even more powerful means for grabbing attention than ever before (Lilleker et al., 2019, p. 2).

The main critique of Dayan and Katz's original approach focuses on the ritualistic and unifying functions of media events, the attempt to exclude any unpleasant or traumatic events, as well as the intense focus on television (Sumiala and Korpiola, 2016, pp. 34-35). In addition, several scholars argue that the initial description of the "media events" outlines a clear correlation between Media coverage and public applause, ignoring the ideological structure of social classes, as well as the potential challenges towards a given status-quo, which are inscribed in several "media events" (e.g. Fiske, 1994; Kellner, 2003; Cottle, 2006; Kyriakidou, 2008; Mihelj, 2008; Rothenbuhler, 1998).

If we attempt to summarize the different considerations around the theory of media events in one definition, we could argue that "media events are specific, full of symbolism, representations of mediated communication, which have a specific thematic core, they can be found in the content of different Media and they "reach" a wide range of audiences and participants (Couldry et al., 2010, p. 12). In short, media events include a number of features: first, the live broadcast and the organization focusing on media coverage, since they are pre-planned and advertised. Thus, media events are not spontaneous events, as they are usually carefully prepared, announced in advance, and intensely anticipated, since they are something that is projected outside the usual routine of the Media. At the same time, media events are characterized by a focus on personality: each media event projects a "hero"/protagonist in the face of an individual or individuals (Mitu, 2016, pp. 233-234).
In this light, the public addresses of the Greek Prime Minister Kyriakos Mitsotakis fall-in structural terms-into the category of media events, as they are pre-announced television events, they interrupt the "normal" flow of media content, they are broadcasted live, they are directed, they address and are viewed by a large audience, as shown by the relevant viewership measurements (youweekly.gr, 2020), and they are characterized by the focus on the personality of the Greek prime minister, who acts as "hero".

Apart from media events, Kyriakos Mitsotakis' public addresses constitute "speech events" as well (Mey, 2001, p. 219). Publicly articulated political discourse is pre-planned, since political actors usually carefully plan their speeches, in order to justify/legitimize action or no action or an ideological position on a specific issue. This "legitimization" deserves special attention in political discourse, since, through their public speeches, political leaders seek to justify their political agenda and to maintain or alter the direction of a whole nation (Reyes, 2011, p. 783). Politicians harness their power, from their status and position, to explain or justify acts in a specific way to elicit people's support. In this vein, political discourse constitutes an example of persuasive speech, organized and conceived to legitimize political goals (Cap, 2008). Van Leeuwen (2007, p. 92, 2008, pp. 105-106) underlines four main categories of legitimization:

1. Authorization, that is legitimation by reference to the authority of tradition, custom, and law, and of persons in whom the institutional authority of some kind is vested.

2. Moral evaluation, that is, legitimation by (often very oblique) reference to value systems.

3. Rationalization, that is, legitimation by reference to the goals and uses of institutionalized social action, and to the knowledge, society has constructed to endow them with cognitive validity.

4. Mythopoesis, that is, legitimation conveyed through narratives whose outcomes reward legitimate actions and punish non-legitimate actions.

These forms of legitimation can occur separately or in combination. They can be used to legitimize, but also to de-legitimize, and to critique. Throughout the deployment of these categories of legitimization, there is a general propagandistic strategy that permeates the discursive construction of reality: the constant creation of two sides, groups, and perspectives that allows for the construction of 'otherness', a division between "us" and "them", between "good" and "bad" following a Manichean rationale for (re)constructing reality (Reyes, 2011; Poulakidakos, 2014). As described by Rojo (1995, p. 50), this division establishes an inclusive 'us' and an exclusive 'them', portraying the excluded in a negative way as mad, irrational, immoral, evil, etc.

The pre-planned, ritualistic, emotional, "unifying" and "emergent" nature of media events, and their orientation to attract large audiences, along with the intentional and persuasive character of speech events, reveal their inherently propagandistic nature. Propaganda constitutes a deliberate, strategically planned, mainly political communication practice, which is exercised through the dissemination of propagandistic discourse through the mass Media (Poulakidakos, 2014, p. 53), hence discourse that seeks to serve the aims of the propagandist.

The intentional nature of propaganda, the fact that it addresses a wide audience and serves ideological purposes aligned with the interests of the propagandist (Shabo, 2008; Auerbach and Castronovo, 2013) are consistent with fundamental parameters of media and speech events. Following the same thread of thinking, media and speech events are carriers of propagandistic discourse. Propagandistic discourse seeks to achieve its desired results by addressing both the emotion and the logic of the audience, in 
order to evoke their sympathy in favor of the propagandist. Evocation to feelings can include techniques aimed at triggering either positive emotions (hope for the future, patriotism, sincerity, determination, altruism, flattery) and/or techniques aimed at provoking negative emotions (fear, uncertainty, impasse/deadend, false dilemma) (Poulakidakos, 2014). The propagandistic method of the evocation to feelings resembles the "legitimization through emotions", in which the appeal to emotions allows social actors to skew the opinion of their interlocutors or audience regarding a specific matter (Reyes, 2011, p. 785). In the case of the appeal to emotions, even though the discourse may include data, there is no new information for the audience. Instead, the data is being used to provoke a sentimental-either positive or negative - "response" on behalf of the audience.

In addition to the attempt to invoke emotion, propagandistic discourse can also be addressed to logic, through the provision of new information consisting either of incomplete data or of data presented in a selective way (Poulakidakos, 2014). In a similar vein, "legitimation through rationality" is enacted when political actors present the legitimization process as a process where decisions have been made after a heeded, evaluated, and thoughtful procedure (Reyes, 2011, p. 786). On several occasions, legitimation through rationality can be achieved through the use of "expert" voices as well. Voices of expertise are displayed in discourse to show the audience that experts are backing the politician's proposal with their knowledgeable statements (Reyes, 2011, p. 786). The aforementioned legitimization practices through the evocation to feelings and/or logic can be traced in public discourse in various combinations, in order to form meaningful messages that will be disseminated as widely as possible through the different Media, both analog and digital ones.

Drawing on this literature, this study offers a three-fold analysis of K. Mitsotakis' televised public addresses: (a) examines the existence of visual and verbal semantic nation-centric elements according to the media events theory by Dayan and Katz (1992); (b) interrogates the general strategy for the creation of two sides, groups and perspectives that allows for the construction of 'otherness', of an "enemy" (Reyes, 2011; Poulakidakos, 2014); and (c) explores the content to identify the four different categories of propagandistic justification (authorization, moral evaluation, rationalization, mythopoesis), and the verbal evocation to feelings and/or to logic.

Through our focus is on the Greek PM's public addresses, we seek to stress out the fact that the pandemic has created the context for a revival of media events in their "original", nationalist, propagandistic, and ritualistic form as they were described by Dayan and Katz back in the early 1990s, and thus urge towards a more systematic examination of these instances of public communication, especially in times of (health) crises.

\section{Main research question, additional questions, research method}

Based on the aforementioned theoretical framework, the main research question for the purposes of this study is: In which ways does K. Mitsotakis seek to legitimize in his public addresses the Greek governments' policies on tackling the pandemic, under the rationale of (propagandistic) media and speech events?

The main research question is supported by additional research hypotheses and research questions such as:

RH1: Given that an important parameter of the "media events" is that their "grammar" is integrated into native (nation-centric) semantic structures of any given social culture (Dayan and Katz, 1992), we expect to encounter nation-centric visual and/or verbal semantic features characterizing Kyriakos Mitsotakis' public addresses.
RQ1: Does K. Mitsotakis create different "sides" in his public addresses? If yes, which ones?

RQ2: Which legitimization category appears more frequently in the public addresses of Kyriakos Mitsotakis?

RQ3: Do evocations to emotion show an attempt to provoke mainly positive or negative emotions?

For the scopes of the current research and given that we intend to focus on both verbal-linguistic and visual elements of the public addresses of K. Mitsotakis, we implement the multimodal analysis. Kress and Van Leeuwen (1996) use the term multimodality to express the fact that the way we communicate very rarely involves a single form of communication and is realized simultaneously through a number of modes. The combination of these different ways of communication forms multimodality, i.e. combinations of visual, language, sound, etc., in order to form a complete communication process. The study of such a multimodal communication process, multimodal analysis, combines in a common level of detail all modes of communication as semiotic systems themselves, whose possible choices, shapes and grammars can be explored and recorded (Machin, 2007, p. x). At the same time, it shares with traditional semiotic analyzes the assumption that all semiotic forms are social semiotic systems that allow us to negotiate social relations and power relations (Hodge and Kress, 1998). "When we want to form a message, we choose the semiotic means we use. But none of these options are neutral. They are all motivated by self-interest" (Machin, 2007, p. xii). Visual meaning-making options work in tandem with the ways in which language creates ideological forms (Lilleker et al., 2019). In the present research, we examine both visual and verbal-linguistic characteristics of K. Mitsotakis' public addresses about the pandemic under the rationale of the theories of (propagandistic) media events and speech events.

As mentioned above, the public addresses of Prime Minister Kyriakos Mitsotakis on the coronavirus until the end of October 2020 are the research material for the purposes of this study. These addresses took place in chronological order on $11 / 03 / 2020$, 17/03/2020, 19/03/2020, 22/03/2020, 13/04/2020, 28/04/2020, 20/ $05 / 2020,24 / 09 / 2020,22 / 10 / 2020$, and $31 / 10 / 2020$. To these 10 addresses, we add two more: that of $25 / 03 / 2020$, when on the occasion of the national anniversary of March 25 that marks the beginning of the Greek war of independence in 1821, K. Mitsotakis referred extensively to the pandemic, and that of 18/04/ 2020, when during his Easter message, Mitsotakis referred once again to the special conditions, due to the coronavirus. Both the relevant videos and the transcripts of the addresses-all available on the website www.primeminister.gr ${ }^{2}$ - were used for the analysis of the addresses. What is interesting to observe, is that nine out of the 12 of K. Mitsotakis' public addresses under scrutiny took place during the first lock-down, during the allegedly more "successful" period in diminishing the dissemination of the pandemic. After the sharp rise in the cases in early August 2020, the public addresses appear to have become rarer, leaving on several occasions a communication gap to be filled by other government officials. The unit of analysis for both the qualitative and quantitative results is the "statement-bite", hence the section in K. Mitsotakis' speech, which constitutes a meaningful declarative sentence, or a sentence component that could stand as a declarative sentence (Lundell and Ekström, 2010; Hurley and Watson, 2018, p. 2).

\section{Analysis of the public addresses}

RH1: The nation-centric visual and verbal semantic features. In addition to the structural characteristics of the addresses that classify them in the category of media events, we can also locate visual elements in the background of the videos and the speech of 
Q1: 200 years ago the Greeks claimed and became free from slaves. And citizens from slaves. They formed a Nation. And they founded a state of Democracy and Justice. We are called to justify these great values, nowadays, with new content, that of mutual responsibility. Because only united peoples can overcome difficulties" (25/03/2020).

Q2: "Our bravery and our collective strength, our philanthropy, which we often invoke, but now it is time to make it a tangible daily routine. With these principles-united and consolidated-we will succeed. The Greeks will be winners again!" (17/03/2020).

K. Mitsotakis, which focus on the creation of a unifying, in nation-centric terms, framework of meaning. The first element that can be identified is the existence of symbols in the background of the videos that reinforce the logic of reconciliation and social inclusion in nationalistic terms (Dayan and Katz, 1992; Demertzis, 1997). These symbols are the Greek flag and the flag of the European Union that exist in the Prime Minister's Office, which is the background behind the figure of Kyriakos Mitsotakis in almost all addresses, with the exception of the one of March 25, which takes place in an outdoor area with the distinct view to the Acropolis in the background and an olive tree as clear symbolism for the "continuity" of the Greek nation from antiquity until today, and that of April 18 for Easter, which takes place outdoors, without any particular distinguishable symbol in the background of the image. In addition, in some of the addresses that took place in the Prime Minister's office (especially on 11/03/2020, 22/10/ 2020 , and $31 / 10 / 2020$ ), the viewer can discern an image of the Virgin Mary holding Jesus Christ as a child placed in a central position behind the office of K. Mitsotakis, a strong symbol of the Christian Orthodox religion and reminiscent of the central role of the Christian Orthodox doctrine in the formation of the contemporary "Greek identity" (Makris and Bekridakis, 2013, p. 111).

The symbols that are systematically displayed in the background of the PM during the broadcasts, aim at consolidating a framework of ethnocentric sense of "belonging" primarily to the Greek nation-state and secondarily to the EU, which is complemented by the religious dimension that the image provides, highlighting the role of the Christian Orthodox religion in the modern social and political organization of Greece, a fact that is reflected in the Prime Minister's references to the Christian Orthodox faith and church:

"Today, it is not our "beliefs" that are being tested, but our belief in human health. The love for the "neighbor" to which Orthodoxy itself refers. That is why religious duties must also be adapted to reality. The Church of the faithful ones after all, is great" (11/03/2020).

At the same time, especially for the address of March 25, the Acropolis and the olive tree in the background mark the "survival" of Greek culture in the centuries and the "direct connection" of the modern Greek state with ancient Greek culture, a fact which denotes an attempt for the "unification" of the public (Dayan and Katz, 1992, pp. 5-9) in nationalistic terms (Demertzis, 1997; Poulakidakos, 2014).

At the verbal level, the unifying, nation-centric rationale is pervasive in all the addresses under investigation. First of all, the main feature of K. Mitsotakis' speech is the beginning of his speeches in 11 of the 12 addresses with the phrase "my fellow citizens". This appeal contributes to the creation of a unifying framework, a set in which "We all belong together", including the Prime Minister. It should be noted that in some cases the appeals "my compatriots" (22/03/2020) or "my compatriots, anywhere in Greece" (17/03/2020) are following the same rationale, underlining the-aligned with the conservative ideological core of $\mathrm{New}$ Democracy-nation-centric nature of the PM's discourse.

In the same vein, K. Mitsotakis, taking special advantage of the anniversary of March 25, the national celebration day for the
Table 2 Verbal nation-centric semantic features.

\section{Public addresses}

$11 / 03 / 2020$

$17 / 03 / 2020$

$19 / 03 / 2020$

$22 / 03 / 2020$

$25 / 03 / 2020$

$13 / 04 / 2020$

$18 / 04 / 2020$

$28 / 04 / 2020$

$20 / 05 / 2020$

$24 / 09 / 2020$

$22 / 10 / 2020$

$31 / 10 / 2020$

Mean

N

Nation-centric verbal features

4

3

2

6

14

3

3

5

5

1

2

2

50

beginning of the Greek Revolution against the Ottomans in 1821, seeked to enhance his nation-centric rhetoric, and tried to underline the virtues of the "Greek race" (Table 1). These virtues (Table 1, Q2) are the ones that will lead the country out of the pandemic. Especially in this last sentence, K. Mitsotakis-by stressing out the "uniqueness of the Greeks"-makes use of (nation-centric) authorization, hence legitimation by reference to the authority of tradition and custom.

As shown in Table 2, the verbal nation-centric features average 4.17 utterances in all 12 public addresses (total number of 50 features), while the public address with the most relevant references is-as expected-the one of the Greek national Independence Day, on March 25, 2020.

RQ1: The division between "us" and the "other". In addition, the utterance of K. Mitsotakis' speech in first plural works in a similar way, through which he "unites" the government with the citizens in the joint effort to deal with the pandemic, seeking to create a sense of "belonging" to the same side/team, an "us" rationale as opposed to the "other", the enemy (Rojo, 1995) in the form of coronavirus: "we are at the beginning of the battle [against the pandemic], which will be difficult" (17/03/2020), "with discipline and solidarity we repelled the pandemic's first waves" (28/04/2020). In political psychology terms, this positive we-ness creates the conditions where mutual concern and support lead to community resilience (Coman et al., 2021, p. 7).

RQ2: Mythopoesis, authorization, moral evaluation, rationalization Mythopoesis. In tandem with the division between "us" (the good ones) and the "enemy" (in this case the pandemic), we found mythopoesis (Van Leeuwen, 2008, p. 106), since K. Mitsotakison one hand-"rewarded" the citizens by giving praise regarding the treatment of the coronavirus: "with your responsible attitude you tamed the first wave of the virus" (13/04/2020), "successes are judged by many little heroes, and these heroes are each and every one of you" (28/04/2020). 
Q1: "Our first priority is one and non-negotiable: To save lives. Our first care is humans and public health; therefore, my first care is the man. Every Greek woman, every Greek man, every Greek child separately. For their life and health, I will bear any cost!" (17/03/2020).

Q2: "I must put the health and safety of the Greeks again above any other option. This is the debt I owe, and this is what I serve" (31/10/2020).

At the same time, K. Mitsotakis did not fail to praise the health workers ("heroes in green and white T-shirts"-19/03/2020), whom he compares to the leaders of the Greek revolution of 1821 - once again the reference to the Greek history/tradition ("the leaders and arsonists of our time are the doctors and the nurses"-25/03/2020). On the other hand, again under the rationale of mythopoesis, $\mathrm{K}$. Mitsotakis warned the ones that do not abide by the measures or spread misinformation regarding the pandemic:

"Those who behave antisocially will be punished by example. Since they will have committed a double crime: Against the law and against life. The same goes for those who spread the virus of misinformation with non-existent rumors. Because panic is as dangerous as the disease" (17/ 03/2020).

Authorization. In terms of authorization, K. Mitsotakis, underlined his personal authority (van Leeuwen, 2008, p. 106), because of his status as head of the Greek government and representative of the Greek State. This personal authority rationale permeates in almost all public addresses: "I choose to communicate more often. And to inform you personally about the new data, the decisions we make and the plans we draw" (17/03/2020).

In order to enhance this authorization rationale, quite often the speeches of K. Mitsotakis contained expressions that underlined the determination of himself and the government for taking the necessary measures to deal with the pandemic. Strong leadership that will do anything to protect the life of every Greek citizen (Table 3):

Moral evaluation. Quite often K. Mitsotakis sought to complement his argumentation with quotes referring to moral values (van Leeuwen, 2008). Most frequently the Greek PM makes evocations to (social) "solidarity" (in each one of his public addresses), through which he underlines the importance of the "common effort" of the Greek people to abide by the restrictive measures taken by the government. Along with that, K. Mitsotakis refers quite frequently to "discipline" (13/04/2020, 18/04/ 2020), "unity" (25/03/2020), and "responsibility" (18/04/2020). All these positive virtues that permeate K. Mitsotakis' discourse seek to underline the "common effort" against the pandemic and enhance the morale of the Greek citizens, that through the ordeal of the pandemic, transforms itself into a new "national selfconfidence" (28/04/2020).

Rationalization. As far as rationalization is concerned as a means of legitimization, K. Mitsotakis included in all his addresses the basic parameters of the policies that the government implemented or was going to implement either to deal with the pandemic or to mitigate its socio-economic consequences. In order to propagandize the government's financial efforts, K. Mitsotakis repeats these measures in various addresses throughout the whole period of our research.

This idealized presentation of the government's policy initiatives on coronavirus is traceable in K. Mitsotakis' addresses. First of all, he praised the enhancement of the National Health System, especially in his September address (24/09/2020), when he made an account of the actions of the government (Table 4, Q1, Q2). In the same vein, the Prime Minister made several references to policies aimed at boosting economic activity, in order to mitigate the negative financial consequences due to the restrictive measures taken to limit the spread of the pandemic. These financial measures are aimed at relieving business owners and employees/workers (Table 4, Q3). Even though Kyriakos Mitsotakis tried to present himself as the leader who seeks to take care of all the (Greek) people, he was reluctant to introduce special measures related to minority social groups, like immigrants and Roma populations, usually living in deep poverty.

Our quantitative analysis regarding the frequency of the different legitimization categories in the discourse of Kyriakos Mitsotakis showed that the most frequent feature of legitimation is rationalization-appearing 115 times in the addresses under scrutiny-followed by authorization (51 times) and moral evaluation (48 times) (Table 5).

RQ3: Evocation to negative (fear) and/or positive (hope) emotions. In addition to the unifying and legitimizing characteristics of the addresses, it is worth mentioning the utterance of meanings that aim to invoke either negative or positive emotions in order to influence the audience for the benefit of the propagandist. Attempts to invoke both positive and negative emotions can be detected in the sermons under analysis.

When it comes to negative emotions, the Prime Minister articulated expressions that try to hold citizens accountable for dealing with the pandemic by invoking uncertainty; in other words, by seeking legitimization through a (negative) hypothetical future (Reyes, 2011, p. 786; Dunmire, 2007): "Like I said, the second wave is tougher. It now affects all ages, but especially young people. And it pervades regions, cities, and even neighborhoods" (22/10/2020).

Mitsotakis also used the invocation of the feeling of fear, stating that "in Italy they do not have coffins to bury their dead" (19/03/ 2020), and "...we realized how difficult it is to manage the second wave of Covid-19, as everywhere the nightmare has returned sharper" (31/10/2020). It is worth noting that the invocation of fear appears initially in the first addresses, in March, when the first wave of the pandemic appeared in Greece and a general lockdown was imposed from the middle of the month onwards. Then, a similar rationale appears again in the end of October, slightly before the imposing of a second lockdown in early November 2020. Thus, this method is used-among others-to pave the way for the implementation of the most restrictive measures (lockdowns and curfews).

A systematic pattern in the messages of the Greek Prime Minister is their closing with phrases that refer to a hopeful and optimistic future: "It is up to us to bring closer to us the future we desire. And paying attention today, to make tomorrow even brighter and more optimistic. We can and we will do it!" (13/04/ 2020). Taking advantage of the Easter, the most important religious celebration of the Orthodox Christians, he states that "We celebrate Easter at home. But with a look at the coming Renaissance!" (18/04/2020), while at the end of May on the occasion of the upcoming "opening" of the borders in tourism states that "I ask you to make this summer an epilogue to the crisis and a preface to renaissance" (20/05/2020). 
Q1: We are adding beds and intensive care beds, we are buying respirators and consumables. And we hire 2000 nurses and specialists" (19/03/2020). Q2: "We used the summer to shield the National Health System, which from 557 ICU beds last year has almost 1000 now; and stocks of sanitary supplies with a horizon of months. We have hired about 6200 new nurses and doctors, many of whom will remain permanently in the NHS" (24/09/ 2020).

Q3: "It (the government) has spent more than 14 billion to support employees and businesses. And it secures another 10 billion euros in liquidity and additional European funds. Already, 750,000 workers are receiving the 800 -euro boost. Nearly 200,000 unemployed had their benefits extended. In more than 500,000 companies, all tax and insurance obligations have been suspended. And 85,000 scientists have applied for paid distance learning programs" (13/04/2020).

Table 5 Legitimization categories ${ }^{3}$.

\begin{tabular}{lllll} 
Public Address & Authorization & Mythopoesis & Moral evaluation & Rationalization \\
\hline $11 / 03 / 2020$ & 9 & 2 & 4 & 10 \\
$17 / 03 / 2020$ & 9 & 4 & 3 & 11 \\
$19 / 03 / 2020$ & 6 & 4 & 5 & 7 \\
$22 / 03 / 2020$ & 7 & 4 & 7 & 2 \\
$25 / 03 / 2020$ & 3 & 4 & 9 & 11 \\
$13 / 04 / 2020$ & 5 & 4 & 6 & 1 \\
$18 / 04 / 2020$ & 1 & 2 & 6 & 23 \\
$28 / 04 / 2020$ & 3 & 3 & 2 & 15 \\
$20 / 05 / 2020$ & 1 & 1 & 2 & 10 \\
$24 / 09 / 2020$ & 2 & 1 & 1 & 8 \\
$22 / 10 / 2020$ & 2 & 3 & 2 & 12 \\
$31 / 10 / 2020$ & 3 & 1 & 4.00 & 9.58 \\
Mean & 4.25 & 2.75 & 48 & 115 \\
$N$ & 51 & 33 & & \\
\hline
\end{tabular}

\section{Table 6 Evocation to positive and negative feelings.}

\begin{tabular}{lll} 
Public address & Negative feelings & Positive feelings \\
\hline $11 / 03 / 2020$ & 3 & 2 \\
$17 / 03 / 2020$ & 3 & 3 \\
$19 / 03 / 2020$ & 2 & 5 \\
$22 / 03 / 2020$ & 1 & 3 \\
$25 / 03 / 2020$ & 0 & 3 \\
$13 / 04 / 2020$ & 3 & 9 \\
$18 / 04 / 2020$ & 0 & 6 \\
$28 / 04 / 2020$ & 2 & 5 \\
$20 / 05 / 2020$ & 2 & 9 \\
$24 / 09 / 2020$ & 3 & 5 \\
$22 / 10 / 2020$ & 2 & 3 \\
$31 / 10 / 2020$ & 4 & 4 \\
Mean & 2.08 & 4.75 \\
$N$ & 25 & 57 \\
\hline
\end{tabular}

As seen in Table 6, the utterances of positive feelings (mostly in the form of a hopeful and optimistic future), average more than twice the ones of negative feelings (mostly in the form of fear), signifying the predominantly positive emotional approach of the Greek PM. Still, the appeal to negative emotions appears to have a specific rationale as a prelude to the implementation of restrictive measures.

\section{Discussion}

Drawing on theories of media events, speech events and propaganda, the present research, focused on the televised addresses of the Greek Prime Minister Kyriakos Mitsotakis regarding the SARS-CoV-2 with COVID pandemic and more specifically on their verbal and visual characteristics, in order to provide a coherent framework for the analysis of all similar public addresses either in or out of the pandemic context.
The need of the public for "orientation" around the coronavirus (Demertzis, 2020) and the political parallelism that characterizes the dominant Greek Media (Hallin and Mancini, 2004), create the appropriate conditions for the development of propagandistic communication practices in both structural (media events) and content terms (legitimation practices) in the discourse of the speakers. Consequently, media events, as nationcentric, mainly televised, ritual manifestations of modernity, predominantly informing the public from government sources seem to become relevant again (Dayan kaı Katz, 1992).

Such characteristic manifestations are the public addresses of Kyriakos Mitsotakis, which constitute media events, as they are directed to be broadcasted primarily on television, they are announced in advance, they attract the interest of the public, they interrupt the "normal" flow of the program, they abound in symbolisms aspiring to reunite the audience with a nation-centric rationale and they are centered around a hero-protagonist. In addition, the same addresses constitute "speech events", since they are speeches embedded in an institutional activity of a certain kind (Mey, 2001, p. 219), they are pre-planned and seek to justify the governmental decisions and policies, in our case regarding the pandemic.

Our multimodal analysis, focusing on both visual and verbal characteristics of the public addresses of Kyriakos Mitsotakis, showed that the major parameters of his appearances include direct visual and verbal connections to aspects of "Greekness" in a nationalistic rationale. This feature is aligned with the ideological core of the conservative right-wing governing party of $\mathrm{New}$ Democracy, as evident in the pre-electoral campaigns of the party in various elections.

In terms of justifying the governmental decisions regarding the pandemic, Mitsotakis, makes use predominantly of rationalization, seeking to promote the measures his government undertakes 
to tackle the pandemic and its repercussions. At the same time, he makes use of other categories of justification as well, like authorization -mostly by promoting his own institutional role and authority, moral evaluations-focused on enhancing the morale of the people in terms of dealing with the pandemic and the restrictive measures implemented by the Greek government, and-closely connected to the moral evaluations- "mythopoesis", by which he predominantly praises the efforts of the professionals tackling the pandemic.

As regards the evocation to positive and negative emotions, $\mathrm{K}$. Mitsotakis mostly opts for the positive ones, by choosing to close all his addresses with an optimistic message about the future. In addition, especially in times that the pandemic appears to get out of control (especially in September and October addresses), the Greek PM chooses to "warn" the public about the "risks" of an "uncontrolled" pandemic, seeking to justify the then-upcoming second lockdown, which has been active since early November 2020. Quite the opposite is his rationale in the end of the firstsuccessful-lockdown in Greece (late April 2020, May 2020), when he appears to make use of discourse seeking to evoke positive feelings.

All in all, K. Mitsotakis' appears to lean mostly on nationalism, rationalization-through the propagandistic promotion of the governmental actions to tackle the pandemic and its repercussions-and optimism, to address the Greek people regarding the pandemic. In this rationale, K. Mitsotakis seeks to present the effort against COVID as a national one, through the ideological re-definition of the pandemic under a nation-centric rationale. In this respect, the rather numerous (12) public addresses of Kyriakos Mitsotakis since early March (on average more than one per month) have served as a major tool for the communication management of the pandemic on behalf of the Greek government.

The current paper, using the public addresses of the Greek PM as a case study, proposes a framework for the analysis of similar public addresses of other presidents and PMs worldwide, in order to generate comparable data on a significant aspect of the communication tactics of the different governments during the COVID-19 pandemic. Given the wide implementation of similar communication tactics (public addresses on behalf of heads and high-ranking officials of governments worldwide) (Lilleker et al., 2019), the current research could be extended to an international comparative level in order to trace similarities and differences in the public addresses of political leaders in their public addresses/ media events regarding the coronavirus pandemic, especially under the rationale of the extent to which they make use of (nationalistic) connotations, evocation to either positive or negative emotions, and use of specific legitimization methods.

\section{Data availability}

The datasets analyzed during the current study are available in the Dataverse repository: https://doi.org/10.7910/DVN/ULRTRG. These datasets were derived from the following public domain resource: www.primeminister.gr.

Received: 30 December 2020; Accepted: 28 September 2021; Published online: 15 October 2021

\section{Notes}

1 Television viewing in Greece was "skyrocketed" from an average of $5 \mathrm{~h} 20 \mathrm{~min}$ per day in the beginning of March 2020, to $7 \mathrm{~h} 35 \mathrm{~min}$ in March 25, 2020. This trend was stabilized until early May 2020, when a slight decrease took place, though the average time of 2020 remained higher compared to that of 2019 (enainstitute.org, 2020).

2 Last accessed 27 December 2020.

3 Given the primarily qualitative character of the legitimization categories, we have to acknowledge that these categories are not fixed, and often appear rather mixed in a given speech event. For instance, the reference to medical science and expert knowledge to legitimize a measure against the pandemic is also a form of authoritarian legitimacy (based on the authority of the experts), as well as a rationalization strategy. For the scopes of the quantitative classification of the categories, we have classified/ counted the legitimization methods that can fall under both authorization and rationalization twice, assigning them in both categories in order to acknowledge their twofold meaning.

\section{References}

Auerbach J, Castronovo R (2013) The Oxford handbook of propaganda studies. Oxford University Press, Oxford

Bennett L (1999) News: the politics of illusions. Dromeas, Athens

Berkowitz DA (1997) Social meanings of news: a text reader. Sage, London

Boorstin D (1989) From the collection to manufacture of news: a cataclysm of pseudo-events. In: Livieratos K, Frangoulis T (eds) The message of the medium. The explosion of mass communication. Alexandria, Athens, pp. $156-197$

Cap P (2008) Towards the proximization model of the analysis of legitimization in political discourse. J Pragmat 40:17-41

Coman I, Elsheikh A, Gregor D, Lilleker M, Novelli DE (2021) Introduction. Political communication, governance and rhetoric in times of crisis. In: Lilleker D, Coman I, Gregor A, Novelli ME (eds) Political vommunication and Covid-19. Governance and rhetoric in times of crisis. Routledge, New York and London, pp. 1-15

Cottle S (2006) Mediatized rituals: beyond manufacturing consent. Media Cult Soc 28(3):411-432

Couldry N (2000) The place of media power: pilgrims and witnesses of the media age. Routledge, London

Couldry N (2008) Mediation or mediatization? Alternative understandings of the emergent space of digital storytelling'. New Media Soc 10:373-391

Couldry N, Hepp A, Krotz F (2010) Media events in a global age. Routledge, London

Covid19.gov.gr (2020) Daily overview of the covid-19 pandemic in Greece. https:// covid19.gov.gr/covid19-live-analytics/. Accessed 5 Apr 2021

Dayan D, Katz E (1992) Media events: the live broadcasting of history. Harvard University Press, Cambridge, Massachusetts

Debord G (1994) Society of the spectacle. Zone Books, New York

Demertzis N (1997) The nationalist discourse. Ambivalent semantic field and contemporary tendencies. Sakkoulas, Athens

Demertzis N (2002) Political communication. Risk, publicity, Internet. Papazissis, Athens

Demertzis, N (2020) The pandemic as trauma. https://www.dianeosis.org/2020/06/ i-pandimia-os-travma/?fbclid=IwAR1mJIY3vYEjux-GuBa7BM1r0cfrVIjU8E ZkSBjEL-wHudyQ7Xt_iEMqFRc. Accessed 22 Oct 2020

Demertzis N, Eyerman R (2020) Covid-19 as cultural trauma. Am J Cult Sociol 8:428-450

Dunmire PL (2007) "Emerging threats" and "coming dangers": claiming the future for preventive war. In: Hodges A, Nilep C (eds.) Discourse, war and terrorism. John Benjamins Publishing Company, Amsterdam/Philadelphia, pp. 19-44

Eibl O, Gregor M (2021) The Czech Republic: self-proclaimed role models. In: Lilleker D, Coman I, Gregor A, Novelli ME (eds) Political communication and Covid-19. Governance and Rhetoric in Times of Crisis, Routledge, New York and London, pp. 259-268

enainstitute.org (2020) The coronavirus crisis through the mass media and the social media. https://www.enainstitute.org/publication/\%CE\%B7-\%CE\%BA\% CF\%81\%CE\%AF\%CF\%83\%CE\%B7-\%CF\%84\%CE\%BF\%CF\%85-\%CE\%BA\% CE\%BF\%CF\%81\%CE\%BF\%CE\%BD\%CE\%BF\%CF\%8A\%CE\%BF\%CF\%8D\%CE\%BC\%CE\%AD\%CF\%83\%CE\%B1-\%CE\%B1\%CF\%80\%CF\%8C-\%CF\% 84\%CE\%B1-\%CE\%BC\%CE\%BC\%CE\%B5-\%CF\%84/. Accessed 5 Apr 2021

Fiske J (1994) Media matters: everyday culture and political change. University of Minnesota Press, Minneapolis

Garland R, Lilleker D (2021) The UK: from consensus to confusion. In: Lilleker D, Coman I, Gregor A, Novelli ME (eds) Political communication and Covid-19. Governance and rhetoric in times of crisis. Routledge, New York and London, pp. 165-176

Hallin DC, Mancini P (2004) Comparing media systems. Three models of media and politics. Cambridge University Press, Cambridge

Hodge R, Kress G (1998) Social semiotics. Cornell Univerity Press, Ithaca

Hurley P, Watson L (2018) A concise introduction to logic. 13th edition. Cengage Learning, Boston

Kalsnes B, Skogerbø E (2021) Norway: from strict measures to pragmatic flexibility. In: Lilleker D, Coman I, Gregor A, Novelli ME (eds) Political communication and Covid-19. Governance and rhetoric in times of crisis. Routledge, New York and London, pp. 231-238

Katz E, Dayan D (2006) The "Landslide" effect. In: Negrine R, Stanyer J (eds) The political communication reader. Routledge, London, pp. 195-199

Kellner D (2003) Media spectacle. Routledge, London and New York 
Kress G, Van Leeuwen T (1996) Reading images: the grammar of visual design. Routledge, London

Kyriakidou M (2008) Rethinking media events in the context of a global public sphere: exploring the audience of global disasters in Greece. Communications 33(3):273-291

Lilleker D, Veneti A, Jackson D (2019) Introduction: visual political communication. In: Veneti A, Lilleker D, Jackson D (eds) Visual political communication. Palgrave Macmillan, Cham, Switzerland, p 1-13

Lippmann W (1988) Public opinion. Kalvos, Athens

Luhmann N (2000) The reality of the mass media. Polity Press, London

Lundell AK, Ekström M (2010) "Interview Bites" in television news production and presentation. Journal Pract 4(4):476-491

Machin D (2007) Introduction to multimodal analysis. Hodder Arnold, London

Makris G, Bekridakis D (2013) The Greek Orthodox Church and the economic crisis since 2009. Int J Study Christian Church 2(13):111-132

Mey J (2001) Pragmatics. Blackwell Publishing, USA, UK, Australia

Mihelj S (2008) National media events: from displays of unity to enactments of division. Eur J Cult Stud 11(4):471-488

Mitu B (2016) Web 2.0 Media Events: Barack Obama’s inauguration. In: Mitu B, Poulakidakos S (eds) Media Events-a critical contemporary approach. Palgrave Macmillan, London, pp. 230-242

Ólafsson JG (2021) Iceland: no lockdown and experts at the forefront. In: Lilleker D, Coman I, Gregor A, Novelli ME (eds) Political communication and Covid19. Governance and rhetoric in times of crisis. Routledge, New York, NY and London, pp. 239-247

Poster M (1990) The mode of information: poststructuralism and social context. Polity Press, Cambridge

Poulakidakos S (2014) Propaganda and public discourse. The presentation of the MoU by the Greek Media. DssaVinci Books, Athens

Reyes A (2011) Strategies of legitimization in political discourse: from words to actions. Discourse Soc 22(6):781-807

Rojo LM (1995) Division and rejection: from the personification of the Gulf conflict to the demonization of Saddam Hussein. Discourse Secur 6(1):49-80

Rothenbuhler EW (1998) Ritual communication: from everyday conversation to mediated ceremony. Sage, Thousand Oaks

Severin W, Tankard Jr JW (2014) Communication theories: origins, methods and uses in the mass media, 5th edn. Pearson, Essex, UK

Shabo M (2008) Techniques of propaganda and persuasion. Prestwick House, USA

Sumiala J, Korpiola L (2016) Tahrir 2011: Contested dynamics of a global media event. In: Mitu B, Poulakidakos S (eds) Media events- a critical contemporary approach. Palgrave Macmillan, London, pp. 31-52

ThePressproject.gr (2019) ERT, NIS and the General Secretariat of Information and Communication under the direct control of Mitotakis. https:// thepressproject.gr/ypo-ton-elegcho-tou-prothypourgou-mitsotaki-i-efp-ke-ing-enimerosis-ke-epikinonias/. Accessed 3 Apr 2021

ThePressproject.gr (2020) Less than $1 \%$ to the opposition Press for the "We stay at home" campaign. https://thepressproject.gr/ligotero-apo-to-1-
ston-antipolitevomeno-typo-gia-to-menoume-spiti/?fbclid=IwAR0iX7 ANNNy5iqarfBIhhyNWLgj9q1Qiz_xYNGquk123P7PhSfBtYVg2PlA,\%

20https://thepressproject.gr/i-lista-petsa-katangellete-se-diethnesepipedo-gia-adiafania-ke-merolipsia/. Accessed 3 Apr 2021

Thompson J (1999) Modernity and mass media, 2nd edn. Papazisis, Athens

Valenzuela S, McCombs M (2019) The agenda-setting function of Mass Media. In: Stacks DW, Salwen MB, Eichhorn KC (eds) An integrated approach to communication theory and research, 3rd edn. Routledge, New York and London, pp. 99-112

Van Leeuwen T (2007) Legitimation in discourse and communication. Discourse Commun 1(1):91-112

Van Leeuwen T (2008) Discourse and practice. New tools for critical discourse analysis. Oxford University Press, Oxford

Youweekly Team (2020) Mitsotakis' public address: which TV channel reached a viewership high? https://www.youweekly.gr/article/tiletheasi/606228-diaggelmamhtsotakh-poio-kanali-xtyphse-kokkino-se-noymera-thletheashs. Accessed 11 Oct 2020

\section{Competing interests}

The author declares no competing interests.

\section{Additional information}

Correspondence and requests for materials should be addressed to Stamatis Poulakidakos.

Reprints and permission information is available at http://www.nature.com/reprints

Publisher's note Springer Nature remains neutral with regard to jurisdictional claims in published maps and institutional affiliations.

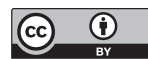

Open Access This article is licensed under a Creative Commons Attribution 4.0 International License, which permits use, sharing, adaptation, distribution and reproduction in any medium or format, as long as you give appropriate credit to the original author(s) and the source, provide a link to the Creative Commons license, and indicate if changes were made. The images or other third party material in this article are included in the article's Creative Commons license, unless indicated otherwise in a credit line to the material. If material is not included in the article's Creative Commons license and your intended use is not permitted by statutory regulation or exceeds the permitted use, you will need to obtain permission directly from the copyright holder. To view a copy of this license, visit http://creativecommons.org/ licenses/by/4.0/.

(c) The Author(s) 2021 